\title{
Efficacy and safety of ozonated autohemotherapy in patients with hyperuricemia and gout: A phase I pilot study
}

\author{
LIAN-YUN LI and JIA-XIANG NI \\ Department of Pain Therapeutic Center, Xuanwu Hospital, Capital Medical University, Beijing 100053, P.R. China
}

Received March 30, 2014; Accepted August 4, 2014

DOI: 10.3892/etm.2014.1951

\begin{abstract}
Gout is a common form of arthritis; however, there are currently no effective therapies available. Ozonated autohemotherapy $\left(\mathrm{O}_{3}\right.$-AHT) is a controversial, but successful method of treatment for a number of diseases. The present study is the first pilot study investigating the application of $\mathrm{O}_{3}$-AHT in patients with hyperuricemia and gout. In total, 10 patients diagnosed with gout were recruited and subjected to $\mathrm{O}_{3}$-AHT. Self-reported pain visual analog scale (VAS) scores and creatinine clearance values were evaluated prior to (T0), during (after the fifth session of $\mathrm{O}_{3}$-AHT treatment; 1-4 weeks; T1) and following the treatment course (5-28 weeks; T2). At $\mathrm{T} 1$, the creatinine clearance rate of the patients significantly increased from 105.14 \pm 35.33 (T0) to $121.45 \pm 44.52 \mathrm{ml} / \mathrm{min}$ $(\mathrm{t}=2.165, \mathrm{P}=0.062)$, while the pain VAS score decreased from $5.35 \pm 2.78$ (T0) to $3.30 \pm 2.21(\mathrm{t}=2.004, \mathrm{P}=0.076)$. However, at $\mathrm{T} 2$, the creatinine clearance rate decreased slightly to $111.15 \pm 36.52 \mathrm{ml} / \mathrm{min}$, and no statistically significant difference was observed from the value at $\mathrm{T} 0(\mathrm{t}=1.723, \mathrm{P}=0.123)$. The pain VAS score further decreased to 2.30 $\pm 2.66(\mathrm{t}=2.628, \mathrm{P}=0.027)$. In conclusion, $\mathrm{O}_{3}$-AHT decreased the creatinine clearance rate and the pain VAS scores of patients with hyperuricemia and gout; thus, may be a potential effective therapeutic approach.
\end{abstract}

\section{Introduction}

Gout is a common form of arthritis. Elevated uric acid levels are observed in the blood of gout patients (hyperuricemia), resulting from the dysfunction of purine metabolism, increased uric acid formation and deposition. Other common gout characteristics are recurrent acute arthritis, tophus, joint deformity and gouty nephropathy, accompanied by hypertension, hyperlipemia, renal and cardiovascular diseases (1-3).

The worldwide prevalence of gout has doubled within the past three decades (4). It was reported that 6.1 million

Correspondence to: Professor Jia-Xiang Ni, Department of Pain Therapeutic Center, Xuanwu Hospital, Capital Medical University, 45 Changchun Road, Beijing 100053, P.R. China

E-mail: nijxcmu@163.com

Key words: ozone, autohemotherapy, gout, hyperuricemia individuals were suffering from gout in America in 2010, constituting $1-2 \%$ of the adult population (5). In East China, the incidence rate was found to be $1.14 \%$ (6); thus, gout is becoming an increasingly important issue for public health.

Hyperuricemia is the most important risk factor in the development of gout, and epidemiological studies have demonstrated that the increasing incidence of gout is closely associated with diet, life style, medical care and lifetime extension (1,7-10). The Health Professionals Follow-up Study and National Health and Nutrition Examination Survey III revealed that dietary patterns had a significant influence on gout incidence $(11,12)$. In particular, a high intake of meat, fish, beer and soft drinks was identified to be closely associated with increased rates of gout incidence, while a high intake of coffee, vitamin $\mathrm{C}$ and low-fat food was associated with reduced gout rates. Studies have suggested that excessive consumption of fructose also contributes towards an increased gout incidence. Although an unhealthy diet was the main cause of gout, genetic factors, renal function and medication, such as diuretics, also played a crucial role in disease development $(3,13,14)$.

Almost all regular treatments administered to gout patients show side-effects and limitations. The use of non-steroidal anti-inflammatory drugs has been found to aggravate renal failure $(15,16)$, hypertension and cardiovascular diseases (17) in gout patients, while glucocorticoid drugs have been shown to aggravate diabetes and hyperlipemia (18). In spite of the adverse effects of these drugs, long-term use remains very common for the treatment of gout. An effective gout therapy to replace the traditional treatment methods has yet to be developed, and efficient clinical recommendations for gout treatment are also unavailable (19).

Ozonated autohemotherapy $\left(\mathrm{O}_{3}\right.$-AHT) is a controversial, but successful method of treatment for a number of diseases. To date, various studies have demonstrated that $\mathrm{O}_{3}$-AHT exhibits beneficial effects as an adjuvant therapy in patients with hepatitis B (20), diabetes, degenerative eye disease, complex regional pain syndrome, ischemic peripheral vascular disease (21) and osteonecrosis of the jaw $(22,23)$. However, studies reporting the role of ozone in the therapy of gout are rare. In a preliminary study, $\mathrm{O}_{3}$-AHT was demonstrated to alleviate the pain of cancer patients, and during the treatment, a decline in the blood uric acid levels was detected. Based on these observations, a pilot study was designed to investigate the application of $\mathrm{O}_{3}$-AHT in gout patients. 
Table I. Patient demographics and baseline disease characteristics.

\begin{tabular}{|c|c|c|c|c|c|c|c|}
\hline No. & $\begin{array}{c}\text { Age } \\
\text { (years) }\end{array}$ & $\begin{array}{c}\text { BMI } \\
\left(\mathrm{kg} / \mathrm{m}^{2}\right)\end{array}$ & $\begin{array}{l}\text { Creatinine } \\
\text { clearance } \\
(\mathrm{ml} / \mathrm{min})\end{array}$ & $\begin{array}{l}\text { Onset and } \\
\text { region of gout }\end{array}$ & Tophus & $\begin{array}{l}\text { Pain VAS } \\
\text { score }\end{array}$ & Combined diseases \\
\hline 1 & 43 & 26.57 & 69.91 & $\begin{array}{l}\text { 2005, right meta- } \\
\text { tarsophalangeal joint }\end{array}$ & + & 8 & $\begin{array}{l}\text { Noninfectious } \\
\text { periodic fever syndrome }\end{array}$ \\
\hline 2 & 24 & 34.29 & 159.38 & 2010 , right ankle joint & - & 5 & $\begin{array}{l}\text { Allergic to shrimp; } \\
\text { family history of gout }\end{array}$ \\
\hline 3 & 39 & 24.62 & 98.88 & 2006, right ankle joint & - & $8-9$ & $\begin{array}{l}\text { Allergic to seafood } \\
\text { and erythromycin; } \\
\text { history of hepatitis A }\end{array}$ \\
\hline 4 & 43 & 24.21 & 130.28 & 2007 , general joint pain & - & 0 & Isn-Ab positive \\
\hline 5 & 43 & 31.74 & 84.42 & 2008 , general joint pain & - & 5 & $\begin{array}{l}\text { History of left knee surg- } \\
\text { ery; sulfanilamide allergy }\end{array}$ \\
\hline 6 & 35 & 29.92 & 118.21 & 2009, left ankle joint & - & 3 & $\begin{array}{l}\text { Rheumatoid } \\
\text { factor-negative }\end{array}$ \\
\hline 7 & 33 & 32.72 & 158.23 & 2009 , general joint pain & - & 5 & $\begin{array}{l}\mathrm{HBsAb}-, \mathrm{HBeAb}-\text { and } \\
\mathrm{HBcAb} \text {-positive }\end{array}$ \\
\hline 8 & 54 & 26.12 & 57.82 & 2006 , right toe joint & + & $9-10$ & $\begin{array}{l}\text { Type II diabetes; } \\
\text { allergic to cold air }\end{array}$ \\
\hline 9 & 59 & 23.03 & 82.96 & 2005 , left toe joint & - & 5 & NK cell count of $28 \%$ \\
\hline 10 & 40 & 27.64 & 91.02 & 2006 , right toe joint & - & $4-5$ & Type II diabetes \\
\hline
\end{tabular}

BMI, body mass index; VAS, visual analog scale; HBsAb, hepatitis B surface antibody; HBeAb, hepatitis B e antibody; HBcAb, hepatitis B core antibody; NK cells, natural killer cells; Isn-Ab, anti-insulin antibody.

\section{Materials and methods}

Patient characteristics. In total, 10 patients that had been diagnosed with gout were recruited for the study, including six males and four females, with ages ranging between 24 and 59 years. Two of the patients suffered from tophus, and three cases were diagnosed with acute gout attack. The clinical data were obtained from patient medical records. The study was approved by the Ethics and Academic Committees of the Capital Medical University (Beijing, China), and informed consent was obtained from all participants. The patients received standard $\mathrm{O}_{3}$-AHT at the Department of Pain Therapeutic Center of Xuanwu Hospital (Capital Medical University).

Procedure. Screening criteria were based on the European League Against Rheumatism diagnosis standard for gout (24). The exclusion criteria comprised the main conditions known to change the concentration of uric acid in the blood: i) Deficiency of glucose-6-phosphate dehydrogenase; ii) severe allergic diseases; iii) use of angiotensin-converting enzyme inhibitors; iv) hyperthyroidism; v) thrombopenia; vi) severe cardiovascular diseases; vii) severe renal impairment (creatinine clearance rate of $<30 \mathrm{ml} / \mathrm{min}$ ); and viii) mental diseases. Patients who did not provide consent for participation in this trial were also excluded.

After screening, the 10 patients were treated with $\mathrm{O}_{3}$-AHT (1-4 weeks) and followed-up for 5-28 weeks. A commercially available ozone generator (Hyper Medozon Comfort;
Herrmann Apparatebau GmbH, Kleinwallstadt, Germany) and Solar $8000 \mathrm{M}$ patient monitor (GE Healthcare, Pittsburgh, PA, USA) were used. During $\mathrm{O}_{3}$-AHT, 200-ml samples of the patient's blood was mixed with $20 \mathrm{ml}$ sodium citrate $(3.8 \%)$, and exposed to an oxygen-ozone mixture with an ozone concentration of $50 \mu \mathrm{g} / \mathrm{ml}$, for $5 \mathrm{~min}$. Next, the blood was transfused back to the same patient. $\mathrm{O}_{3}$-AHT was performed three times a week, for a total of ten times for each patient.

Data collection. Pain visual analog scale (VAS) scores (range, 0-10; a score of 0 indicated 'no pain' and higher scores indicate higher pain intensity) were reported for all the patients. Routine blood examinations (analyzing the count of leukocytes, erythrocytes, hemoglobin, platelets, neutrophils, neutrophil ratio, lymphocytes, lymphocyte ratio, mononuclear cells, eosinocytes and basophils) were performed for all the patients, as well as a comprehensive metabolic panel (analyzing the concentrations of serum creatinine, uric acid, high-density lipoprotein, low-density lipoprotein, total cholesterol, albumin, glucose and alanine aminotransferase). Immunological parameters ( $\operatorname{Ig} \mathrm{A}, \operatorname{IgG}, \operatorname{Ig} \mathrm{M}$, complement component 3 and complement component 4) were also examined. Data were collected prior to (T0), during (after the fifth session of treatment; 1-4 weeks; T1) and following the full course of treatment (5-28 weeks; T2).

Statistical analysis. Statistical analyses were performed using SPSS software, version 17.0 (SPSS, Inc., Chicago, IL, USA). Experimental data obtained for each patient are presented as 
Table II. Changes in the creatinine clearance rate and pain VAS scores in patients with hyperuricemia and gout treated with $\mathrm{O}_{3}$-AHT.

\begin{tabular}{|c|c|c|c|c|}
\hline Time point & $\begin{array}{c}\text { Creatinine } \\
\text { clearance }(\mathrm{ml} / \mathrm{min})^{\mathrm{a}}\end{array}$ & $\begin{array}{l}\text { Paired t-test } \\
\text { (vs. T0) }\end{array}$ & $\begin{array}{l}\text { Pain VAS } \\
\text { scores }^{b}\end{array}$ & $\begin{array}{l}\text { Paired t-test } \\
\text { (vs. T0) }\end{array}$ \\
\hline T0 & $105.14 \pm 35.33$ & - & $5.35 \pm 2.78$ & - \\
\hline $\mathrm{T} 1$ & $121.45 \pm 44.52$ & $\begin{array}{l}\mathrm{t}=2.165 \\
\mathrm{P}=0.062\end{array}$ & $3.30 \pm 2.21$ & $\begin{array}{l}\mathrm{t}=2.004 \\
\mathrm{P}=0.076\end{array}$ \\
\hline $\mathrm{T} 2$ & $111.15 \pm 36.52$ & $\begin{array}{l}\mathrm{t}=1.723 \\
\mathrm{P}=0.123\end{array}$ & $2.30 \pm 2.66$ & $\begin{array}{l}t=2.628 \\
P=0.027\end{array}$ \\
\hline
\end{tabular}

${ }^{\mathrm{a} C}$ Creatinine clearance reference range, $80-120 \mathrm{ml} / \mathrm{min}$; ${ }^{\mathrm{b}}$ pain VAS score reference range, $0-10 . \mathrm{O}_{3}$-AHT, ozonated autohemotherapy; VAS, visual analog scale; T0, prior to treatment; T1, following the fifth session of treatment; T2, following the course of $\mathrm{O}_{3}$-AHT treatment.

A

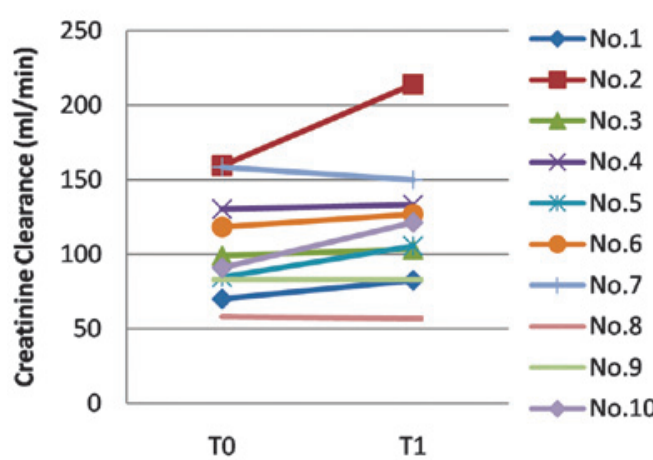

C

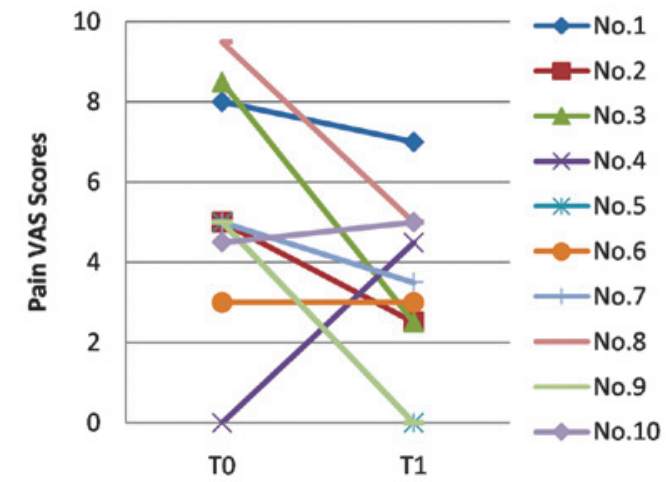

B

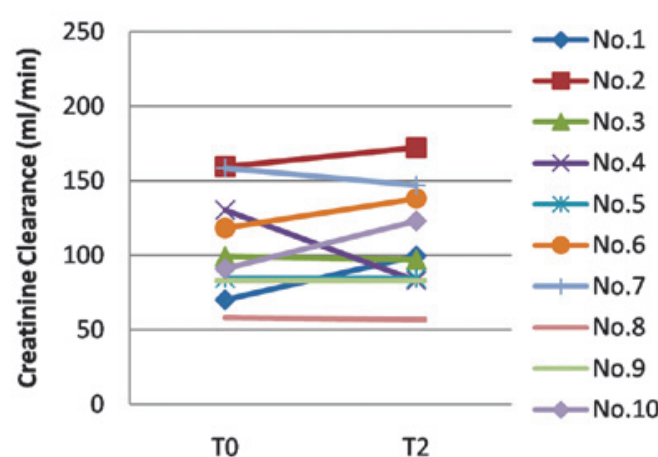

D

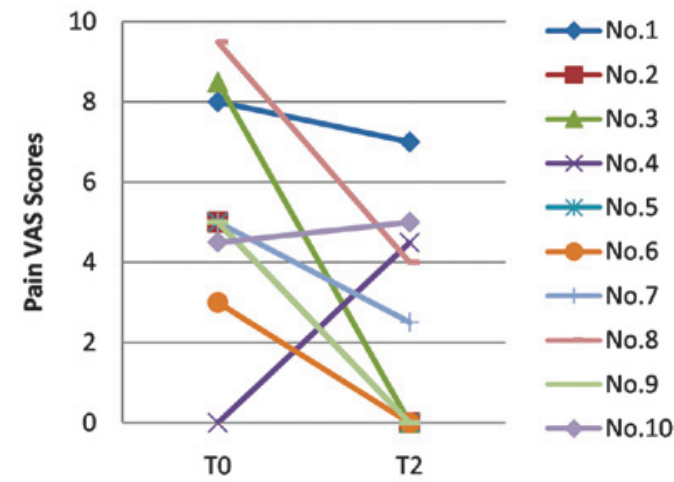

Figure 1. Changes in the creatinine clearance rate and pain VAS scores in patients with hyperuricemia and gout receiving ozonated autohemotherapy $\left(\mathrm{O}_{3}\right.$-AHT). Comparison of the creatine clearance rates between (A) T1 vs. T0 and (B) T2 vs. T0. Comparison of the pain VAS scores between (C) T1 vs. T0 and (D) T2 vs. T0. VAS, visual analog scale; T0, prior to treatment; T1, following the fifth session of treatment; $\mathrm{T} 2$, following the course of $\mathrm{O}_{3}$-AHT treatment.

the mean \pm standard deviation. The Student's t-test (for paired samples) was used when the variances of two normal distributions were assumed to be equal. Under non-normal distribution or unequal variance conditions, the Wilcoxon signed-rank test was performed. Due to the small sample size of this pilot study, $\mathrm{P}<0.1$ was considered to indicate a statistically significant difference, in order to reduce the probability of type II error.

\section{Results}

General patient characteristics. All 10 patients completed the treatment protocol. Nine patients underwent 10 courses of $\mathrm{O}_{3}$-AHT, while one patient received seven courses of $\mathrm{O}_{3}$-AHT.
Four cases were diagnosed with obesity (body mass index, $>28 \mathrm{~kg} / \mathrm{m}^{2}$ ), and two cases were diagnosed with type II diabetes mellitus and renal dysfunction (creatinine clearance rate, $<80 \mathrm{ml} / \mathrm{min}$ ). Six patients had food or medicine allergies, and one case was diagnosed with hyperlipemia. Patients had not been routinely administered drugs that may have affected the level of uric acid for at least six weeks prior to and during the study. The average time from the first diagnosis of gout was 4.5 years (range, 1-7 years; Table I).

Efficacy on the creatinine clearance rate and pain VAS scores. In general, a complete clinical response with an increased creatinine clearance rate and decreased pain VAS scores was achieved for all the patients (Table II; Fig. 1). 
The creatinine clearance rate, which normally ranges between 80 and $120 \mathrm{ml} / \mathrm{min}$, was determined to be $105.14 \pm 35.33 \mathrm{ml} / \mathrm{min}$ prior to $\mathrm{O}_{3}$-AHT (T0). After the fifth session of $\mathrm{O}_{3}$-AHT (T1), the creatinine clearance rate increased to $121.45 \pm 44.52 \mathrm{ml} / \mathrm{min}$, which was significantly higher compared with the value at $\mathrm{T} 0(\mathrm{t}=2.165, \mathrm{P}=0.062)$. However, after the course of $\mathrm{O}_{3}$-AHT (T2), the creatinine clearance rate decreased slightly to $111.15 \pm 36.52 \mathrm{ml} / \mathrm{min}$, and exhibited no statistically significant difference with the creatinine clearance rate at $\mathrm{T} 0(\mathrm{t}=1.723, \mathrm{P}=0.123)$.

Pain VAS scores are one of the most commonly used measures of pain intensity. At T0, the patients showed a mean pain VAS score of $5.35 \pm 2.78$. The mean pain VAS score decreased to $3.30 \pm 2.21$ at $\mathrm{T} 1$, which was significantly lower than the score at $\mathrm{T} 0(\mathrm{t}=2.004, \mathrm{P}=0.076)$. The mean VAS score further decreased to $2.30 \pm 2.66$ at $\mathrm{T} 2$, and a statistically significant difference was observed when compared with the pain VAS score at T0 $(\mathrm{t}=2.628, \mathrm{P}=0.027)$.

Safety. Patients with hyperuricemia and gout showed good tolerance to the $\mathrm{O}_{3}$-AHT. No serious adverse reactions, including a rash, low blood pressure, abnormal liver function and abdominal pain, or acute gout attacks were observed during the treatment course. One patient developed mild dizziness and nausea during the seventh treatment session; however, normality was regained after $2 \mathrm{~h}$.

\section{Discussion}

Ozone is a gas found naturally in the Earth's atmosphere, but can be produced from oxygen for medical use. Ozone exhibits wound-healing and antimicrobial properties, which may promote tissue repair and regeneration (25). Reactive oxygen species (ROS) and lipid oxidation products (LOPs) generated from the acute oxidative stress reaction of water, ozone and serum antioxidants have been reported to promote red blood cells to provide oxygen to ischemic tissues, resist viral infections by activating the immune system and release protective factors, including nitric oxide, carbon monoxide and platelet-derived growth factor $(22,25,26)$.

$\mathrm{O}_{3}$-AHT is a new complementary therapeutic technology, during which physicians inject medical grade ozone gas into blood collected from a patient, and subsequently intravenously transfuse the blood back to the same patient. $\mathrm{O}_{3}$-AHT has recently developed into a modern medical approach that is widely used in the treatment of hepatitis $\mathrm{B}$, diabetes and numerous other diseases (22). However, the efficacy and safety of $\mathrm{O}_{3}$-AHT in hyperuricemia and gout treatment remains unknown.

Low-dose ozone treatment has been universally accepted as a treatment for lumbar disc herniation, arterial atherosclerosis, ischemic cerebrovascular disease and a number of other diseases. Accurate measurements of ozone using a spectrophotometer have revealed that an ozone concentration of $20-80 \mu \mathrm{g} / \mathrm{ml}$ is not toxic. A preliminary clinical study identified that $\mathrm{O}_{3}$-AHT using this dose appeared to have an effect on pain alleviation in cancer patients. In addition, during this treatment, a decrease in the level of uric acid in the blood was observed, indicating a therapeutic potential for the application of $\mathrm{O}_{3}$-AHT in cases of hyperuricemia and gout. To explore the safety and efficacy of $\mathrm{O}_{3}$-AHT, a phase I clinical trial was performed in patients with hyperuricemia and gout.

In the present study, the creatinine clearance rate of patients receiving $\mathrm{O}_{3}$-AHT increased significantly, reaching values even beyond the reference range. Self-reported pain VAS scores were also significantly decreased after five sessions of $\mathrm{O}_{3}$-AHT, and were further decreased by $50 \%$ following completion of the treatment course. These results indicated that $\mathrm{O}_{3}$-AHT may be a potential complementary medical approach for patients with hyperuricemia and gout.

Neutrophils and macrophages are the main inflammatory cells in the pathological process of gout. It has been reported that monosodium urate causes the death of neutrophils and the release of lysozyme, and its metabolism may be influenced by the ROS and LOPs generated from the acute oxidative stress reaction resulting from $\mathrm{O}_{3}$-AHT (27-29). However, the exact mechanisms require further research.

However, limitations of the present study also require addressing. Firstly, the study involved a small group of patients; therefore, further studies involving more patients are required in order to confirm the observations. Secondly, a double-blind randomized controlled trial, which may provide further evidence, was unable to be performed due to the small study size population. Finally, in the current study, only the potential therapeutic role of $\mathrm{O}_{3}$-AHT was addressed; thus, the exact mechanisms and pathways require further elucidation. However, as a pilot clinical study, the present study has provided the basics for further research into the therapeutic potential and molecular mechanisms of $\mathrm{O}_{3}-\mathrm{AHT}$ in patients with hyperuricemia and gout.

In conclusion, $20 \mu \mathrm{g} / \mathrm{ml}$ ozone was identified to be an effective biological dose for $\mathrm{O}_{3}$-AHT, achieving a good curative effect and safety in patients with hyperuricemia and gout. Thus, low-dose $\mathrm{O}_{3}$-AHT may be a potential effective approach for hyperuricemia and gout patients. Further studies with a larger sample size, as well as investigations into the underlying mechanisms of $\mathrm{O}_{3}$-AHT, are required in the future.

\section{References}

1. Wallace KL, Riedel AA, Joseph-Ridge N and Wortmann R: Increasing prevalence of gout and hyperuricemia over 10 years among older adults in a managed care population. J Rheumatol 31: 1582-1587, 2004.

2. Choi HK and Ford ES: Prevalence of the metabolic syndrome in individuals with hyperuricemia. Am J Med 120: 442-447, 2007.

3. Kramer HM and Curhan G: The association between gout and nephrolithiasis: the National Health and Nutrition Examination on Survey III, 1988-1994. Am J Kidney Dis 40: 37-42, 2002.

4. Smith E, Hoy D, Cross M, et al: The global burden of gout: estimates from the Global Burden of Disease 2010 study. Ann Rheum Dis 73: 1470-1476, 2014.

5. Smith EU, Díaz-Torné C, Perez-Ruiz F and March LM: Epidemiology of gout: an update. Best Pract Res Clin Rheumatol 24: 811-827, 2010.

6. Miao Z, Li C, Chen Y, et al: Dietary and lifestyle changes associated with high prevalence of hyperuricemia and gout in the Shandong coastal cities of Eastern China. J Rheumatol 35: 1859-1864, 2008 .

7. Doherty M: New insights into the epidemiology of gout Rheumatology (Oxford) 48 (Suppl 2): ii2-ii8, 2009.

8. Roddy E, Zhang W and Doherty M: The changing epidemiology of gout. Nat Clin Pract Rheumatol 3: 443-449, 2007.

9. Lawrence RC, Helmick CG, Arnett FC, et al: Estimates of the prevalence of arthritis and selected musculoskeletal disorders in the United States. Arthritis Rheum 41: 778-799, 1988. 
10. Helmick CG, Felson DT, Lawrence RC, et al: Estimates of the prevalence of arthritis and other rheumatic conditions in the United States. Part I. Arthritis Rheum 58: 15-25, 2008.

11. Kim SY, De Vera MA and Choi HK: Gout and mortality. Clin Exp Rheumatol 26 (5 Suppl 51): S115-S119, 2008.

12. Luk AJ and Simkin PA: Epidemiology of hyperuricemia and gout. Am J Manag Care 11 (15 Suppl): S435-S442, 2005.

13. Arromdee E, Michet CJ, Crowson CS, O'Fallon WM and Gabriel SE: Epidemiology of gout: is the incidence rising? J Rheumatol 29: 2403-2406, 2002.

14. Lawrence RC, Felson DT, Helmick CG, et al: Estimates of the prevalence of arthritis and other rheumatic conditions in the United States. Part II. Arthritis Rheum 58: 26-35, 2008.

15. Hoskison KT and Wortmann RL: Management of gout in older adults: barriers to optimal control. Drug Aging 24: 21-36, 2007.

16. Cheng HF and Harris RC: Renal effects of non-steroidal anti-inflammatory drugs and selective cyclooxygenase-2 inhibitors. Curr Pharm Des 11: 1795-1804, 2005.

17. White WB: Cardiovascular risk, hypertension, and NSAIDs. Curr Rheumatol Rep 9: 36-43, 2007.

18. Soleimani M: Dietary fructose, salt absorption and hypertension in metabolic syndrome: towards a new paradigm. Acta Physiol (Oxf) 201: 55-62, 2011.

19. Keenan RT, O'Brien WR, Lee KH, et al: Prevalence of contraindications and prescription of pharmacologic therapies for gout. Am J Med 124: 155-163, 2011.

20. Chernyshev AL, Filimonov RM, Karasev AV, et al: Combined treatment including ozonotherapy of patients with viral hepatitis. Vopr Kurortol Fizioter Lech Fiz Kult 3: 19-22, 2008 (In Russian).

21. De Monte A, van der Zee H and Bocci V: Major ozonated autohemotherapy in chronic limb ischemia with ulcerations. J Altern Complement Med 11: 363-367, 2005.
22. Bocci V, Borrelli E, Travagli V and Zanardi I: The ozone paradox: ozone is a strong oxidant as well as a medical drug. Med Res Rev 29: 646-682, 2009.

23. Ripamonti CI, Cislaghi E, Mariani L and Maniezzo M: Efficacy and safety of medical ozone $(\mathrm{O}(3))$ delivered in oil suspension applications for the treatment of osteonecrosis of the jaw in patients with bone metastases treated with bisphosphonates: Preliminary results of a phase I-II study. Oral Oncol 47: 185-190, 2011.

24. Zhang W, Doherty M,Pascual E, Bardin T, et al: EULAR evidence based recommendations for gout. Part I: Diagnosis. Report of a task force of the Standing Committee for International Clinical Studies Including Therapeutics (ESCISIT). Ann Rheum Dis 65: 1301-1311, 2006.

25. Bocci V: Ozone as Janus: this controversial gas can be either toxic or medically useful. Mediators Inflamm 13: 3-11, 2004.

26. Bocci V, Valacchi G, Corradeschi F, et al: Studies on the biological effects of ozone: 7. Generation of reactive oxygen species (ROS) after exposure of human blood to ozone. J Biol Regul Homeost Agents 12: 67-75, 1998.

27. Hoffstein S and Weissmann G: Mechanisms of lysosomal enzyme release from leukocytes. IV. Interaction of monosodium urate crystals with dogfish and human leukocytes. Arthritis Rheum 18: 153-165, 1975.

28. Kozin F, Ginsberg MH and Skosey JL: Polymorphonuclear leukocyte responses to monosodium urate crystals: modification by adsorbed serum proteins. J Rheumatol 6: 519-526, 1979.

29. Nuki G: Colchicine: its mechanism of action and efficacy in crystal-induced inflammation. Curr Rheumatol Rep 10: 218-227, 2008. 